\title{
The Role of "Radical Change" in Medium of Instruction and Its Impact on Learning
}

\author{
Mirza Naveed Shahzad \\ University of Gujrat, Gujrat, Pakistan \\ Sadia Sajjad \\ FJ Girls College, Gujrat, Pakistan \\ Mirza Ashfaq Ahmed \\ Faculty of Management and Administrative Sciences, University of Gujrat, Gujrat, Pakistan \\ Zahid Asghar \\ Quaid-i-Azam University, Islamabad, Pakistan
}

\begin{abstract}
English language as Medium of Instruction (MOI) plays the central role in the students' learning at university level. Therefore, how well students would fare in academic achievement depends largely on their English language abilities. This study explores how much students are comfortable about learning in English language, and the relevant associated problems and constraints faced by them. For this retrospective study, a self made questionnaire was used to collect the data from $\mathbf{3 0 0}$ university students by using the stratified random sampling with proportional allocation. To confirm the chosen variables Confirmatory factor analysis is used and the Discriminant analysis is used to determine the most discriminating variable among the selected variables. The characteristics of different groups of students based on their Agreement, Disagreement and Neutral Opinion regarding MOI are explored by using Cluster analysis. It is argued that productive learning process utilizing English language does not only rely on the English language knowledge, but also on other factors such as students' ability and talent, communication skills, supportive teachers and supportive home environment, motivation and the right attitude toward language, just to name a few. The findings revealed that the majority of the students had a positive attitude and were highly motivated towards the use of English as a MOI. The conclusion also indicated that, English medium background, supportive home environment, right learning strategies and English communication skills played an important role in enhancing the positive attitude and motivation to improve their academic performance and achievements.
\end{abstract}

Index Terms - medium of instruction (MOI), English language, discriminant analysis, cluster analysis

\section{INTRODUCTION}

Generally, it is believed that a highly motivated student with the right attitude would always strive for excellence in the educational career. Learning is not only a process of communication and interaction between the teacher and students but it has foremost and broad role in learning process. Learners actively engage in the learning process through discussion, reading, writing, analysis and evaluation, rather than passively absorbing Instructions. To learn, students have to communicate, and it is a procedure through which information is exchanged among individuals, it demands a shared understanding of language. Language, being a tool of communication, allows people to convey ideas, facts and feelings to each other and express their communicative needs. There are more or less 5,000 languages in use in the world today. Every advanced country has its own national language.

It is tremendously important requirement to have full command on language in which a person is learning. Passing of knowledge, information and skills appropriately is possible only, when MOI is acceptable and is according to the mantel state of the learner. Often those who don't have a grip on a particular language are excluded from conversations.

In the history and in present times MOI has been the blazing issue in many countries of the world. Like so many other countries, Pakistan is also a multilingual country. In addition to Urdu, being national language, which serves as the "link language" for all the provinces, there are other languages that are used as the MOI at country, provincial and regional academic levels. Though Urdu is the national language of the country, all official correspondence is made in English at educational institutes, banks, courts, industries etc. so status of English language can never be denied in the country. As a result in Pakistan MOI is an unresolved issue due to overwhelming of other local and native languages.

Although Urdu has accorded the status of the national language, but for international communication for any purpose it is not the medium. It is renowned as the dominating language in the world. The development of the world has been connected with the dominance of the English. In the whole world English is used by millions of native and non-native speakers. According to (Crystal, 2003), there are roughly 430 million Second language (L2) users and 330 million 
Home/First language(L1) users of English language. Today English is a window on the world through which we view and keep in touch with all the modern developments in the arts, science, industry, medicine and other fields. It enables students to read original books by famous authors, scientists, doctors, engineers and specialist. It helps to get familiar with modern research, as its spreading on the Internet in recent year's shows (almost $80 \%$ of the world-wide-webs pages are now written in English). Not any other language offers such a wide scope for research and scientific studies.

There are number of possible factors that can affect the learning, when the MOI is a foreign language and as a result the academic performance of students in higher education. Due to broad and varying factors, this study complements the most important factors reviewed from literature. The factors that can affect learning in L2 depends on the learner's social and economic background, formal schooling in primary language and so on (Collier, 1988). If a student has an English medium background, he/she can manage English MOI easily in higher education as compare to a student who has less studied other subjects in English or not studied at all.

The home environment has an enormous influence on the student's psychological, emotional, social and economic state. Since the parents are the first socializing agents in an individual's life, so the language in which they communicate is the language which serves the individual for his/her whole life. Students with poor learning abilities in English language may obtain lower grades than those with better learning abilities. Communication skill is also a basic requirement; it includes writing, listening, reading and speaking abilities. To understand what the question requires and how to provide the best possible answer with respect to sentence structure and importance depends on this skill.

Other than adopting the suitable learning strategies, excelling in English language also requires that students have the right attitude toward the language and learning. To be interested in English language is vital as interest serves as the "pull" factor that propels other behaviors like finding extra information from other sources, making sure concepts are clear, and learning the necessary terminologies, to name a few.

Motivation is a sort of desire for learning. It is an inner condition which activates behavior and gives it proper direction; energizes and directs objective behavior. Motivation of the students is also very significant factor for learning in L2. Students mainly had a short-term goal of passing the courses only. The role of teacher is a fundamental factor in the success for learning in L2. The productive interaction with teachers is very essential.

It is a long held debate in Pakistan whether the MOI should be the universally renowned English or the regional language. Both the options have pros and cons. English is essential when an individual goes into professional life, regional language has an advantage of being easily understood, so helping the students grasp the right information and understand better. However, in higher education and especially the professional courses English medium is a necessity. It would not be considered proper that streams like, Medicine, Engineering, MBA or any technical course can be imparted in a regional language. Government, specifically the Department of Education, has recognized the fact that English is the international language, and has to be adopted as MOI in teaching because of the availability of resources and references in English. Failures among students to secure jobs after graduating are often linked to their inability to communicate effectively in English. It is often reminded that to successfully compete in today's globalized world, mastery of the English language is a necessity. Not having command on English language results in reducing students' level of self confidence. They feel hesitation in expressing their views and in making questions. They feel embarrassment because of having language deficiency. They have to struggle hard with gaining competence not only in the subject but also in the language. The understanding of textual material has been shown to be problematic for them and the readability of the text is difficult for them. Although they are aware that English can win them good jobs with rich salary if they are good in English, but the biggest factor is that in spite of studying English as a subject, they do not get exposure to situations where they can use English or they can observe how English is used by others. Their knowledge is in fact, restricted to writing an examination in English.

In Pakistan, very little systematic research has been published, considering MOI and to explore the characteristics of students who accept English as MOI. The findings not only provide factors that can affect the learning of university students regarding MOI. But also provide practical support to students for developing themselves and help the teachers in identifying their role. The research objectives are:

1. To identify and confirm the factors those are paramount for student's concept development in a second language.

2. To determine the most discriminating factor among those who accept and those who do not accept English as medium of instruction.

3. To explore the characteristics of the students who accept, do not accept or neutral about English as a medium of instruction.

\section{LITERATURE REVIEW}

The reviewed literature from the past studies conducted in different countries about the controversial issue of MOI, showed different factors that can effect the learning process and as a result the academic achievement of a student. Cotterall (1999) used factor analysis and identified factors which the literature suggests are important in successful language learning. Chamot and Dinary identified the strategies that effective learners use for reading and writing in a foreign language by focusing on high rated and low rated students. Talib (2009) highlighted that good learning outcome does not only rely on the teaching methodology but also on factors such as students' ability and talent, language proficiency, and the right attitude toward learning. Parveen, et al. (2007) claimed that learner should be familiar with 
the medium of instruction for sound learning. Guzman (2006) analyzed the English language learning difficulties of students relative to their sociolinguistic competence, motivation and cultural factors GÖMLEKSIZ (2001) explored the factors in the second language acquisition process i.e. cognitive development, socio-economic and cultural background, ability to acquire a language, age and motivation of the learner. Cooper (1987) explored the effect of Second Language on Test Scores, Intelligence and Achievement and found that Economic background, did not affect students' performance. Jalaluddin, et al. (2009) and Berman and Cheng (2000) determined the Perceived difficulties in academic achievement with English language and argued that the inability to communicate in English has been one of the reasons of high unemployment rate, Environment not conducive to language learning further add to the problem. Chimbganda (2010) suggested that 'high-proficiency' students are able to select the main points and to combine them to form a coherent summary.

Wilkinson (2005) reported how language affected the teaching of content in English medium programme. Teachers make changes to instructional methods, allowing in some cases code switching because teaching through English demands more time so that terms and concepts can be explained. Vandal (2004) found that in Pakistan there was variation in the medium of instruction, majority follow the government prescribed Urdu language and a small number offer instructions in the English Language. Duxbury and Tsai (2010) identified that motivation, student beliefs, student personality, teacher interactions, student-background in the language, and cooperative learning influenced levels of foreign language anxiety among foreign language students at a university. Okan (2009), Vaezi (2008) and Obeidat (2005) explored that talented students were very enthusiastic about learning English they had very high motivation and positive attitudes towards learning English. They were more inclined towards bilingualism and interactively motivated to study second language and there was no significant differences in student's motivation related to sex, parent's proficiency and level of study. Wei (2007) examined the motivational pattern in relation to the anxiety of English learners. Fakeye (2010), Bidin, et al. (2009) and Al-Tamimi and Shuib (2009) claimed that there was a positive relationship between Students' Attitude and their academic achievement in English Language and revealed that most of students had positive attitudes towards the social value and educational status of English.

\section{SURVEY METHODOLOGY}

The population of the study consisted of the students of B.S (Hons) both natural and social sciences, those who had completed the first semester and are studying at University of Gujrat. Stratified random sampling has been applied, in order to ensure the adequate representation of each disciple in the sample. To determine the sample size of the study a table developed by Bartlett, et al. (2001) was used. Since the total population size is 1170 and the data is categorical so the sample size ' $n$ ' is taken as $25 \%$ of the population with 0.05 margin of error. By using the proportional allocation method a sample of 300 students is selected. Firstly, strata's are made with respect to the pure and general sciences and then each designed stratum is further stratified on the basis of departments. And finally these stratums are stratified according to the gender of students. 118 students are from natural science (50 males and 68 females) and 182 students from social science (105 males and 77 females). Self made questionnaire as a main instrument was employed, it consisted of two parts. First part was about demographic information and second part constituted the factors selecting through literature review and measured through total number of 67 questions and measured using the 5-point Likert Scale.

Descriptive statistics are carried out for all items involved in the study. Confirmatory factor analysis is used to confirm the factors. Discriminant analysis and Two-Step Cluster Analysis are used to fulfill the main objectives of the study. The cluster analysis is an exploratory data analysis tool aims at sorting different objects into groups in a way that the degree of association between two objects is maximal if they belong to the same group and minimal otherwise. The term cluster analysis does not identify a particular statistical method or model, as do Discriminant analysis and factor analysis. Often we don't have to make any assumptions about the underlying distribution of the data. There are numerous ways to sort cases into groups, Hierarchical cluster analysis, k-means cluster, and two-step cluster are the major types of clustering; in this study two-step cluster analysis is used. It provides a simple profile of individuals and also suggests how groups of units are determined such that units within groups are similar in some respect and unlike those from other groups.

\section{Results AND DisCUSSION}

In order to observe the study performance of students, the results of descriptive statistics are calculated for all variables but results of some of the important variables are discussed here. These results provide simple summaries about the sample and the measures.

\section{A. Descriptive Analysis}

Average marks of the respondent in English course (intermediate), out of 200 are 128.53 and its S.D is 26. Mean GPA of students is 3.06 out of 4.00 and Its S.D is 0.48 which shows that GPA of students is close to mean. $34.3 \%$ of the respondents belong to rural areas and $65.7 \%$ are from urban areas. $48.7 \%$ of the respondents had never studied in an English medium school at all, while $27.7 \%$ of the respondents had throughout studied in an English medium school. At 
intermediate level $31.3 \%$ of the respondents studied in Urdu medium and $68.7 \%$ studied in an English medium. 39.3\% of the respondents speak Urdu at home, 29\% speak Punjabi and only 3\% of them also speak English at home. 54.7\% respondents can speak Urdu most fluently, $17.7 \%$ can speak Punjabi most fluently and only $11.3 \%$ can speak English fluently. These results indicate that students like English language but they do not have the exposure to this language as it is not their home language. It also shows that the tendency to use the mixture of English and Urdu is more as compare to use English separately. Total scores are computed by combining the variables within each factor into a single score that replaced the original with new composite variables, to be used for further analysis.

\section{B. Factors that can Affect Learning, While MOI is English}

Firstly, factors are chosen from the reviewed literature that can influence the learning of students in a second language e.g. Educational Background, Home Environment, Attitude, Motivation and so on. Confirmatory factor analysis has been applied for the conformation of these factors. All the selected variables in each factor are confirmed. Most of the factors are meeting the criteria of conformation, as shown in Table 4.1 and can be used for further analysis.

TABLE 4.1:

MEASURES OF GOODNESS OF FIT FOR ALL THE FACTORS THAT CAN AFFECT LEARNING

\begin{tabular}{|c|c|c|c|c|c|c|c|c|c|}
\hline $\begin{array}{l}\text { Recommended } \\
\text { Factors }\end{array}$ & $x$ & 窎 & $\underbrace{5}_{1}$ & $\sum_{\underline{a}}^{\infty} \underset{1}{\mathscr{N}}$ & $\begin{array}{l}\text { Recommended } \\
\text { Factors }\end{array}$ & نج & 窇 & $\underbrace{}_{4}$ & $\sum_{\underline{a}}^{\infty} \mathbb{1}$ \\
\hline Minimum Criteria & $\leq 5$ & $\geq .90$ & $\geq .90$ & $\leq .08$ & Minimum Criteria & $\leq 5$ & $\geq .90$ & $\geq .90$ & $\leq .08$ \\
\hline 1.Educational Background & 4.60 & 0.92 & 0.86 & 0.12 & 6.Class & 3.00 & 0.93 & 0.89 & 0.08 \\
\hline 2.Home Environment & 10.9 & 0.94 & 0.81 & 0.18 & Performance & & & & \\
\hline 3.Learning Strategies & 2.29 & 0.98 & 0.95 & 0.07 & 7.Attitude & 7.00 & 0.88 & 0.78 & 0.15 \\
\hline 4.English Communication & 2.89 & 0.98 & 0.94 & 0.08 & 8.Motivation & 4.50 & 0.91 & 0.84 & 0.11 \\
\hline 5.Academic Performance & 2.76 & 0.98 & 0.94 & 0.08 & 9.Teacher's Role & 2.68 & 0.97 & 0.94 & 0.07 \\
\hline
\end{tabular}

\section{Determination of Most Discriminating Factor}

One of the objectives of the study is to determine the factor, which is playing the most significant role in differentiating among those who accept and those who do not accept English as MOI. To explore that most discriminating factor among the selected factors mentioned in Table 4.1, the technique of discriminant analysis has been applied.

The classification functions are used to assign cases to groups. The Discriminant model assigns the case to the group whose classification function obtains the highest score. All the coefficients of classification function are smaller for those who DO NOT ACCEPT English, as MOI. It suggests that students with less ability in all selected factors do not accept English as MOI. Box's M is 43.281 with F-value 1.131 and P-value 0.271 , so it is not significant. Therefore, population covariance matrices are equal.

The test of equality of group means measure each selected factors potential before the model is created. Each test displays the results of a one-way ANOVA for the independent factors. According to the results in Table 4.2, every variable in Discriminant model is significant except Educational background. Wilks' lambda is another measure of a variable's potential. Smaller values indicate the variable is better at discriminating between groups. The table suggests that the motivation is best discriminator among those who accept and those who do not accept English as MOI, followed by the role of the teacher, academic performance, learning strategies and so on.

TABLE 4.2:

TESTS OF EQUALITY OF GROUP MEANS

\begin{tabular}{|c|c|c|c|c|c|c|c|}
\hline & Wilks' Lambda & $\mathrm{F}$ & Sig. & & Wilks' Lambda & $\mathrm{F}$ & Sig. \\
\hline Educational Background & .993 & 1.438 & .232 & Class performance & .930 & 15.759 & .000 \\
\hline Home environment & .965 & 7.517 & .007 & Motivation & .658 & 107.873 & .000 \\
\hline Learning strategies & .817 & 46.517 & .000 & Teacher role & .782 & 58.027 & .000 \\
\hline English communication skill & .929 & 15.785 & .000 & Academic performance & .802 & 51.443 & .000 \\
\hline
\end{tabular}

In addition to measures for checking the contribution of individual predictors to the Discriminant model, the Discriminant Analysis procedure provides the Eigen values and Wilks' lambda for seeing how well the Discriminant model as a whole fits the data. Wilks' lambda is 0.423 , its smaller value indicate greater discriminatory ability of the function.

Value of Chi square is 175.571 with P-value 0.000; the small significance value indicates that the Discriminant function does better than chance at separating the groups of students. Eigen value is 1.365, supporting the model. Canonical Discriminant Functions reported the multivariate measures of overall model fit. Discriminant function is highly significant (.000) and displays a canonical correlation of .760 . We can interpret it by squaring it. $(0.760)^{2}=$ 0.5776. Thus, 57.76 percent of the dependent variable can be accounted for by this model, which include 8 independent variables.

The classification Table A.1 shows the practical results of using the Discriminant model. Cells on the diagonal of the cross-classification are correct classifications. Cells off the diagonal of the cross classification are incorrect 
classifications. Of the cases used to create the model, 49 of the 53 students who previously do not accept English as MOI are classified correctly. While 4 are classified incorrectly. 146 of the 157 who accept English as MOI are classified correctly. Overall, $92.9 \%$ of the cases are classified correctly. 89.2 percent of the cases not selected are correctly classified by the model.

\section{Determination of Characteristics of Each Group of Student}

The central objective of the study is identifying groups of individuals, whose characteristics are similar and they accept English as MOI but different from individuals in other groups who do not accept or neutral about MOI and thinks that MOI has no influence on their learning. To fulfill this objective the technique of two step cluster analysis is used. The process, by which the number of clusters is chosen, is summarized in Auto-clustering Table A.1. The clustering criterion (Bayesian information Criterion) is computed for each potential number of clusters. It suggests that the smallest BIC is 1995.313 , for which the number of clusters is 3 .

The cluster distribution indicates that out of 300 total cases, no cases were excluded from the analysis. 92 cases are assigned to the first cluster, 185 to the second, and 23 to the third. Number of individuals assigned to the second cluster has the highest percentage of $61.7 \%$. Whereas, percentage of first cluster is 30.70 and third is $7.7 \%$.

The Centroids are shown in Table A.2; it indicates the clusters separated by the factors. It shows the characteristics of the students in cluster 1 who thinks that MOI should be English. They have a very good educational and English medium background with mean 24.3478. Their home environment is supportive regarding English language with mean 18.00. Their learning strategies are better than the students in second and third clusters with mean 21.8696. Their English communication skills are higher than students in rest of the clusters with mean 20.6957. Their Class performance is good with mean 38.2826 and they do not face the language anxiety. They have a positive attitude about learning in English language with mean 35.7391.They have a very high motivation with mean 35.1413 as compare to the students in other clusters, who are neutral or do not accept English as a MOI. The role of their teachers is also very supportive and encouraging towards English language with mean 21.8913. Their overall academic performance is also very good with mean 11.4022 .

The characteristics of the students in cluster 2, who are neutral about the MOI whether it should be English or Urdu reveals that they have a good educational background with mean 21.0108. Their home environment is supportive with mean 16.3027. Their learning strategies are good with mean 19.1189. Their English communication skills are also good with mean 19.7730. Their Class performance is good with mean 34.7405 and they do not face the language anxiety. Although they have a positive attitude about learning in English language with mean 30.8270 but it is less as compare to the students, who accepts English as a medium of instruction. They have a high motivation with mean 29.3243 but it is less as compare to the students in first clusters. The role of their teachers is also supportive and encouraging towards English language with mean 19.4162. Their overall academic performance is also good with mean 10.0811 .

It also reveals the characteristics of the students in cluster 3, who do not accept English as a MOI. They do not have a good educational and English medium background with mean 12.6957. Their home environment is almost as supportive as of those in cluster 2, with mean 16.0870. Their learning strategies are not very good with mean 15.00. Their English communication skills are normal with mean 17.4783. Their Class performance is also not very good with mean 29.5652 and they have to face the language anxiety in classroom. They also have a positive attitude about learning in English language with mean 28.1739 but it is very less as compare to the students, who accepts English as a medium of instruction. Their level of motivation is very low with mean 20.6522 as compare to the students in first and second clusters. The role of their teachers is not as supportive and encouraging towards English language as of first and second cluster students, with mean 15.7391. Their overall academic performance is also not very good with mean 7.9565 . Finally, it can be said that high accepters of English MOI are in first cluster, average accepters are in second cluster and the mean of all the independent variables is less than the average value for the third cluster.

To clarify the properties of the clusters the cluster frequency by the acceptance level is used. It indicates that Cluster 1 is comprised entirely of the students who accept English as a MOI with frequency 92. Clusters 2 contain only the students who are neutral about the MOI whether it should be English or not with frequency 185. Cluster 3 is comprised entirely of the students who do not accept English as a MOI with frequency 23.

\section{Factor-wise Importance}

The "by variable" importance chart for first cluster is shown in Fig. 4.1. The variables on the Y axis are in descending order of importance. Motivation is the most important variable for this cluster while attitude, educational background and role of teacher are also very important variables in this cluster. For determining the significance of each variable the dashed straight up lines mark the critical values. A variable to be significant, its $t$ statistic must exceed the dashed line in either positive or negative way. The importance measures for all of the variables exceed the critical value in this chart except English communication skills, so we can conclude that all of the continuous variables except English communication skills contribute to the formation of the first cluster. It also indicates that for Cluster 1, all the variables takes larger than average values. These results confirm the trends observed by the Centroids results. 


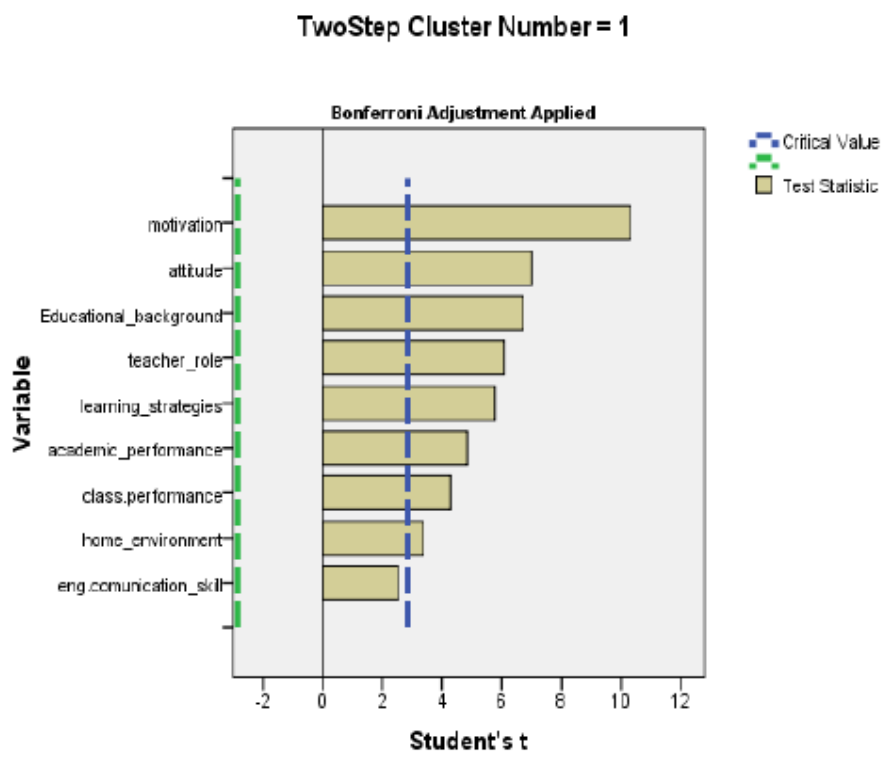

Fig. 4.1: By-variable importance chart for cluster no. 1

The "by variable" importance chart for second cluster is shown in Fig. 4.2. It indicates that Attitude is the most important variable for this cluster while motivation is also very important variables in this cluster. The importance measures for only the variables of attitude and motivation exceeds the critical value in it, so we can conclude that only these two continuous variables contribute to the formation of the second cluster. It also indicates that for Cluster 2, all the variables takes smaller than average values. These results confirm the trends observed by the Centroids results.

The "by variable" importance chart for third cluster is shown in Fig. 4.3. The variables on the Y axis are in downward order of importance. Motivation is the most important variable for this cluster while learning strategies, class performance, role of teacher and attitude are also very important variables in this cluster. The chart for Cluster 2 shows that home environment is not important to the formation of this cluster as it does not exceed the critical value. So we can conclude that all of the continuous variables except home environment contribute to the formation of the third cluster. It also indicates that for Cluster 3, all the variables takes smaller than average values. These results confirm the trends observed by the Centroids results.

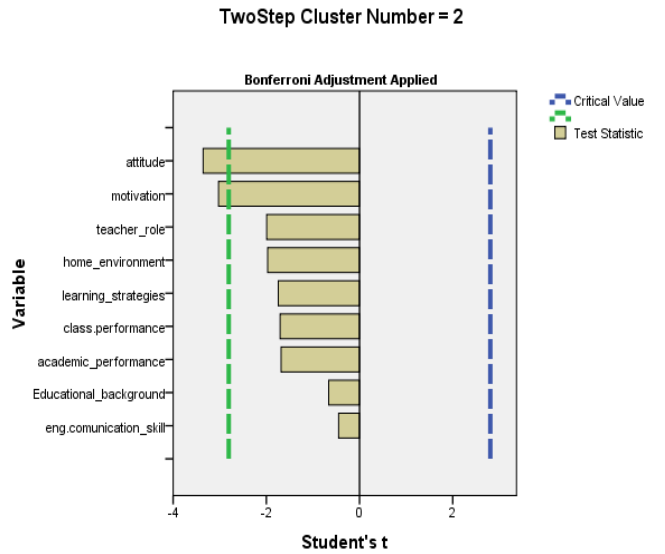

Fig.4.2: By-variable importance chart for cluster no. 2

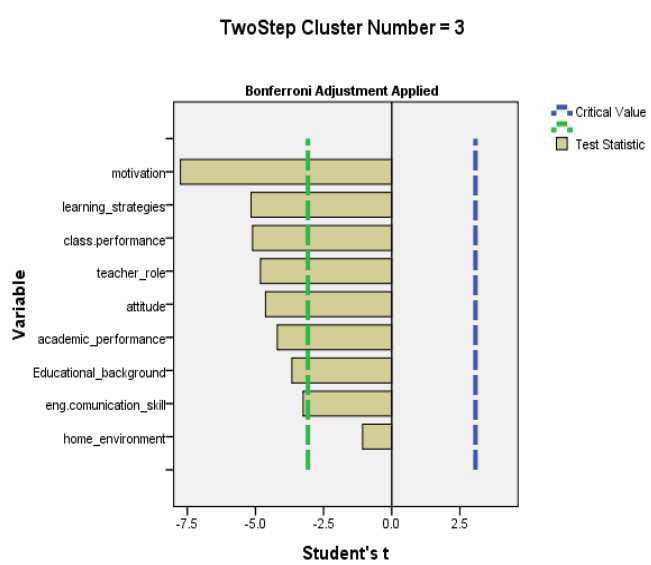

Fig.4.3: By-variable importance chart for cluster no. 3

Through these results we can conclude that students who thinks that MOI should be English, have a very good educational and English medium background, supportive home environment regarding English language, good learning strategies, English communication skills, Class performance and academic performance, and have a positive attitude and very high motivation. The role of their teachers is also very supportive and encouraging towards English language. While the students who are neutral about MOI, although they are good in studies but they lack in positive attitude towards English language and they are less motivated. On the other hand those who think that MOI should not be English are very few and they are not overall good students.

\section{E. Conclusion}


The study examined the effects of MOI on learning of students, when they are learning in a foreign language i.e. English. It also explores that which factor play an important role for measuring student's learning efficiency, and also explore the characteristics of the students who thinks that MOI should be English. The findings showed that almost half of the students think that by improving the speaking skill of English language, they can improve their overall learning in English. Three clusters of students are made by using Two Step Cluster Analysis, first cluster contains the characteristics of students who accept English as a MOI, they are highly motivated and have a positive attitude towards learning in English language and overall they are very good students. Second cluster consist of the characteristics of students who are neutral about MOI whether it should be English or the national language Urdu, although overall they are good students but they are less motivated and do not have a positive attitude towards learning in English language. The third cluster comprised of the characteristics of students does not accept English as a MOI, overall they are not very good students, they do not have a supportive home environment and English medium educational background, therefore they are not motivated and have a negative attitude towards learning in English language. The findings present a picture which confirms that the teacher, the class atmosphere, the educational background, as well as personal characteristics of the student i.e. their learning strategies, attitude and English communication skill will have an influence on the individual's learning. Discriminant analysis suggested that motivation is the most discriminating factor among the selected factors. Results also disclose that most of the students realize the tremendous potential, English language can bring to their learning. They will continue to use English language despite facing problems. Almost all of the students expressed their perception that learning in the English language is a good opportunity for them to be more successful in the future. They argue that teachers must always use English language during lectures to produce successful learning.

\section{F. Limitations of the Study}

Due to financial and time concerns only the students from the University of Gujrat have been included in the study as a respondent. Only the students from the second semester have been taken for observing the impact of language on students learning. Within restricted time frame it does not allow to use a large sample which is required for the reliability of the survey and generalizing findings and making inferences from a sample about the population.

\section{G. Recommendations / Suggestions}

A similar type of study can be conducted for longitudinally collected data, So that it can be observe how medium of instruction, impacts on learning with the passage of time. For high Academic Performance, the students need to improve their Learning Strategies, then their communication Skills which assists them in presentation skills, assignment writing and reading materials related to course. Educators should also motivate by encouraging them to learn English, frequently reminding them of the importance of mastering English; to attain their personal goals such as to further studies, travel abroad, prepare for the working in all over the world. This is due to the fact that some of the respondents are not aware of the purpose of learning English and learn it because it is required in the system. Finally, this study can be expected to pave the way for other exploratory studies on student's learning relative to their language learning.

\section{APPENDIX}

TABLE A.1:

CLASSIFICATION RESULTS

\begin{tabular}{|c|c|c|c|c|c|c|}
\hline \multirow{6}{*}{ 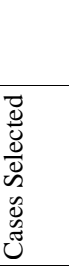 } & & \multicolumn{5}{|c|}{ Predicted Group Membership } \\
\hline & & & \multirow{5}{*}{$\begin{array}{l}\text { Don't Accept } \\
\text { Accept } \\
\text { Don't Accept } \\
\text { Accept }\end{array}$} & Don't Accept & Accept & Total \\
\hline & Original & Count & & 49 & 4 & 53 \\
\hline & & & & 11 & 146 & 157 \\
\hline & & $\%$ & & 92.5 & 7.5 & 100.0 \\
\hline & & & & 7.0 & 93.0 & 100.0 \\
\hline & Cross-validated $^{\text {a }}$ & Count & \multirow{4}{*}{$\begin{array}{l}\text { Don't Accept } \\
\text { Accept } \\
\text { Don't Accept } \\
\text { Accept }\end{array}$} & 49 & 4 & 53 \\
\hline & & & & 14 & 143 & 157 \\
\hline & & $\%$ & & 92.5 & 7.5 & 100.0 \\
\hline & & & & 8.9 & 91.1 & 100.0 \\
\hline \multirow{4}{*}{ 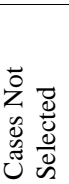 } & Original & Count & \multirow{4}{*}{$\begin{array}{l}\text { Don't Accept } \\
\text { Accept } \\
\text { Don't Accept } \\
\text { Accept }\end{array}$} & 14 & 3 & 17 \\
\hline & & & & 4 & 44 & 48 \\
\hline & & $\%$ & & 82.4 & 17.6 & 100.0 \\
\hline & & & & 8.3 & 91.7 & 100.0 \\
\hline
\end{tabular}

a. Cross validation is done only for those cases in the analysis. In cross validation, each case is classified by the functions derived from all cases other than that case.

b. $92.9 \%$ of selected original grouped cases correctly classified.

c. $89.2 \%$ of unselected original grouped cases correctly classified. 
TABLE A.2:

AUTO CLUSTERING

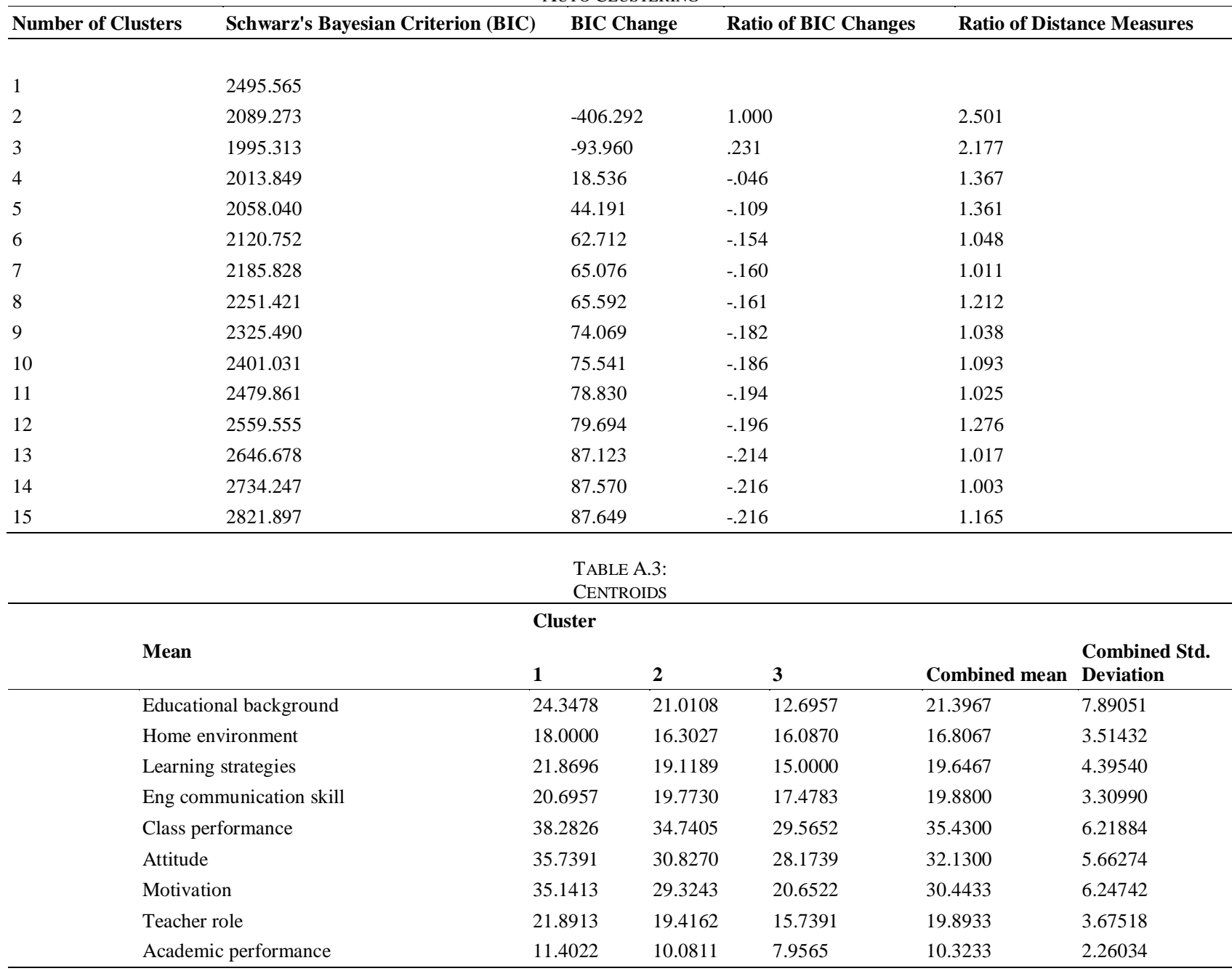

\section{REFERENCES}

[1] Al-Tamimi, A. and Shuib, M. (2009). Motivation and Attitudes towards Learning English: A Study of Petroleum Engineering Undergraduates at Hadhramout University Of Sciences and Technology. GEMA Online Journal of Language Studies, 9(2), 2955.

[2] Bartlett, J. E., Kotrlik, J. W. and Higgins, C. C. (2001). Information Technology, Learning, and Performance Journal, 19(1).

[3] Berman, R. and Cheng, L. (2000). English academic language skills: Perceived difficulties by undergraduate and graduate students, and their academic achievement. Canadian journal of applied linguistics, 4(1-2), 25-40.

[4] Bidin, S., Jusoff, K., Aziz, N. A., Salleh, M. M. and Tajudin, T. (2009). Motivation and Attitude in Learning English among UiTM Students in the Northern Region of Malaysia. CCSE English Language Teaching, 2(2), 16-20.

[5] Chamot, A. U. and Dinary, P. B. Children's Learning Strategies in Language Immersion Classrooms. Language Research Projects, Georgetown University, 1-32.

[6] Chimbganda, A. B. (2010). Summary Production: A Topographical Analysis of the Strategies Used by University ESL First Year Science Students. The Asian EFL Journal, 12(2), 117-143.

[7] Collier, V. P. (1988). The Effect of Age on Acquisition of a Second Language for School. New Focus. The National Clearinghouse for Bilingual Education. No: 2, Winter: 1987-1988.

[8] Cooper, T. C. (1987). Foreign Language Study and SAT-Verbal Scores. The Modern Language Journal, 71(4), $381-387$.

[9] Cotterall, S. (1999). Key variables in language learning: what do learners believe about them? System, 27(4), 493-513.

[10] Crystal, D. (2003). English as a global language (second edition). Cambridge University Press.

[11] Duxbury, J. G. and Tsai, L. (2010). The effects of cooperative learning on foreign language anxiety: A comparative study of Taiwanese and American Universities. International Journal of Instruction, 3(1), 3-18.

[12] Fakeye, D. O. (2010). Students' Personal Variables as Correlates of Academic Achievement in English as a Second Language in Nigeria. $J$ Soc Sci, 22(3), 205-211.

[13] GÖMLEKSIZ, M. N. (2001). The effects of age and motivation on second language acquisition. Firat University Journal of Social Science, 11(2), 217-224.

[14] Guzman, A. B., Albela, E. J. A., Nieto, D. R. D., Ferrer, J. B. F. and Santos, R. N. (2006). English Language Learning Difficulty of Korean Students in a Philippine. 
[15] Jalaluddin, N. H., Awal, N. M. and Bakar, K. A. (2009). Linguistics and Environment in English Language Learning: Towards the Development of Quality Human Capital. European Journal of Social Sciences, 9(4), 627-642.

[16] Obeidat, M. M. (2005). Attitude and motivation in second language learning. Journal of faculty of Education, 18(22), 1-17.

[17] Okan, Z. and Duygu, I. (2009). Gifted students' perceptions of learning English as a foreign language. Educational Research and Review, 4 (4), 117-126.

[18] Parveen, S., Gopang, A. S. and Shaikh, S. I. (2007). Language and learning: Impact of a language on cognative development of secondary school children. The Sindh University Journal of Education, 37(1), 93-106.

[19] Talib, O., Luan, W. S., Azhar, S. C. and Abdullah, N. (2009). Uncovering Malaysian Students' Motivation to Learning Science. European Journal of Social Sciences, 8(2), 266-276.

[20] Vaezi, Z. (2008). Language Learning Motivation among Iranian Undergraduate Students. World Applied Sciences Journal, 5 (1), 54-61.

[21] Vandal, S. H. (2004). Art Education in Pakistan: A case study of bringing art to school children at the informal level. Paper presented at the UNESCO Regional Expert Symposium on Arts Education in Asia, Hong Kong.

[22] Wei, M. (2007). The Interrelatedness of Affective Factors in EFL Learning: An Examination of Motivational Patterns in Relation to Anxiety in China. TESL-EJ, 11(1), 1-23.

[23] Wilkinson, R. (2005, Sep 2).The impact of language on teaching content: Views from the content teacher. Conference at Helsinki.

Mirza Naveed Shahzad is a doctoral student and working on the dissertation in the domain of Income Distribution and Inequality. He has earned his M.Phil degree in Statistics from Qauid-i-Azam University, Islamabad, Pakistan in 2008, In M.Phil degree his area of research was the mixture distributions. He is interested in the area of Econometrics, Mixture Distributions, Applied Statistics and Probability etc.

He has serve as a LECTURER in different colleges and universities. He teaches up to M.Phil/M.S level. He supervised many applied and pure work theses in Statistics of M.Sc/B.S (Hons) students. He is working on number of research paper in the domain of Mixture Distribution and Applied Statistics.

Sadia Sajjad is a LECTURER in the Fawara Chowk College Gujrat. She did her B.S (Hon) from University of Gujrat. She is a distinguish student and got Gold Medal in the B.S (Hons).

Mirza Ashfaq Ahmed is a doctoral student and working on the dissertation in the domain of political marketing. He has earned his master degree in business administration from London Metropolitan University, London, United Kingdom in 2006. He is interested in the area of Commercial Marketing, Political Marketing, Social Network Theory, Game Theory etc.

$\mathrm{He}$ has the intensive work profile and currently working in the University of Gujrat as a SENIOR LECTURER in Faculty of Management and Administrative Sciences. He has the track record of working as ASSISTANT MARKETING MANAGER in Park Royal Cash and Carry, London, U.K., Service Shoe Industry, Gujrat, Pakistan as MANAGER COORDINATION ISO, PRODUCTION MANAGER AND TECHNICAL MANAGER and Qarshi Pharmaceutical Industry Lahore, Pakistan as a QUALITY ANALYST.

$\mathrm{He}$ is working on number of research paper in the realm of Brand Management and Political Marketing. One of them has been acknowledged as BEST PAPER AWARD in the international conference, 2010 held in London, UK.

Zahid Asghar is an ASSISTANT PROFESSOR in Statistics, Quaid-i-Azam University, Islamabad. He got his doctorate degree from Pakistan institute of Development of Economics (PIDE), and having extensive working experience in teaching and research. He is supervising many $\mathrm{PhD}$ and M.Phil dissertation in the area of Econometrics, Time Series and Applied Statistics. 